\title{
APRENDIZAGEM COLABORATIVA: OFICINA DE EMPREENDEDORISMO PARA O TURISMO RURAL EM NOVA PONTAL - ROSANA, SP
}

\author{
Renata Ribeiro, Fábio L. Violin \\ Universidade Estadual Paulista - UNESP. Curso de Turismo, Rosana - SP. E-mail: renata@rosana.unesp.br
}

\section{RESUMO}

Nova Pontal - SP possui características naturais e culturais somados à hospitalidade de pessoas que trabalham no campo na produção de alimentos variados. Em 2012 iniciou-se o Projeto Turismo em Rosana: Aprendendo com a Natureza fim de qualificar pessoas para o turismo rural. A ideia central foi qualificar e organizar roteiro de visitação a estudantes das Escolas Municipais de Rosana -SP. Nessa perspectiva a oficina de empreendedorismo teve como tema, demonstrar técnicas de hospitalidade e marketing numa visão ampla e simples, com o intuito de busca da valorização das pessoas, na geração de confiança de seus produtos e de seu modo de vida, da singularidade do campo e variedade de produtos produzidos. Ensinar foi essencial ao empreendedorismo e ao desenvolvimento do turismo rural em Nova Pontal - SP.

Palavras-chave: turismo, hospitalidade, empreendedorismo, qualificação, visitação.

\section{COLLABORATIVE LEARNING: WORKSHOPENTREPRENEURSHIP FOR RURAL TOURISMINNOVA PONTAL -ROSANA,SP}

\begin{abstract}
Nova Pontal - SP has natural and cultural features added to the hospitality of people working in the field in the production of various foods. In 2012 began the Tourism Project in Rosana: Learning from Nature in order to qualify people for rural tourism. The central idea was to qualify and organize script visitation to students in the public school Rosana-SP. From this perspective, entrepreneurship workshop had as its theme, demonstrate techniques of hospitality and marketing a broad and simple vision, in order to search for valuing people, generating trust in their products and their way of life, the uniqueness of the field and variety of products produced. Teaching was essential for entrepreneurship and development of rural tourism in New Pontal - SP. Keywords: tourism, hospitality, entrepreneurship, skills, visitation.
\end{abstract}




\section{INTRODUÇÃO}

O Assentamento Nova Pontal está localizado no município de Rosana -SP e foi criado em 1998. Em sua distribuição geográfica possui 123 lotes distribuídos ao longodo rio Paranapanema na divisa com o Estado do Paraná. Essa região possui recursos naturais e culturais potenciais ao desenvolvimento do turismo rural $^{1}$ ou do turismo no espaço rural.

Aproposta de mobilização para o turismo rural trouxe aos docentes e discentes do Curso de Turismo a possibilidade emdesenvolver pesquisas e práticas nas várias temáticas do turismo; entre elas, de roteiros rurais, de empreendedorismo, de hospitalidade, associativismo, economia entre outros. A equipe multidisciplinar trabalhou em uma perspectiva de envolver o produtor ruralna sua própria qualificação a partir de um objeto de estudo prático, comum a todos, em que a participação e ação deveria ser coadjuvante no processo de empreender uma nova atividade em meio rural. O objetivo em gerar roteiros de visitação nos sítios exigiu qualidades e capacidades próprias de criação e empreendedorismo.

O conceito de empreendedorismo não é unidimensional, antes apresenta-se como complexo e carregado da contribuição de outras áreas, portanto, multidisciplinar, o que explica em parte a grande quantidade de conceitos associados ao termo. Dentro de uma visão tradicional poder-se-ia dizer que os empreendedores são aqueles que buscam oportunidade de negócio seja por necessidade seja pelo senso de oportunismo

Ainda assim, tem-se basicamente dois motivadores para a ação empreendedora: a necessidade e/ou a oportunidade. Apregoa que deve ser feita a distinção entre o empreendedorismo que reflete busca voluntária de oportunidades e o empreendedorismo que reflete a necessidade de participar da cadeia produtiva pela ausência por exemplo de um emprego ou como forma de aumentar a renda familiar.

Drucker (2005), defini empreendedores como aqueles que criam algo novo, algo diferente; mudando ou transformando valores. O autor prossegue defendendo a ideia de que a surgimento da economia empreendedora é um evento de ordem tanto cultural e psicológica, quanto econômico e tecnológica, nos quais a inovação figura como valioso instrumento dos empreendedores ao explorarem as oportunidades de um novo negócio.

Já as ações de Marketing visam fundamentalmente a geração de elementos que de forma específica se propõem a gerar satisfação na relação entre uma organização e seus clientes, sejam reais ou potenciais. Kotler e Keller (2006) especificam que Marketing é "[...] um processo social

\footnotetext{
${ }^{1}$ Considera-se nesse estudo: turismo rural são as atividades realizadas pelo visitante que estão diretamente relacionadas à lida no campo como colheita de produtos, lida com o gado, alimentação de animais. Por turismo no espaço rural entende-se: o visitante realiza atividades de lazer que não estão diretamente ligadas às atividades cotidianas de trabalho no ambiente rural.
} 
por meio dos quais pessoas e grupos de pessoas obtêm aquilo de que necessitam e o que desejam com a criação, oferta e livre negociação de produtos e serviços de valor".

Marketing é apontado pela literatura como sendo capaz de agregar valor a produtos e serviços com foco na atração, estímulo e gestão da demanda tendo como base a identificação de necessidades e desejos dos clientes ou consumidores dentro de um ou mais segmentos de mercado. (SWARBROOKE, J. e HORNER, 2002; COBRA, 2005; KOTLER e KELLER, 2006).

Este artigo explicita a importância emsensibilizar pessoas do meio rural quanto a importância do ato de empreender como elemento auxiliar à formatação de um atrativo turístico em ambiente rural a partir da técnica de formatação de um roteiro ruralparticipativo, em que a experiência local e pessoal atenda aos ensejos de geração de valores às questões naturais, culturais em um ambiente rural, de características particularizadas por questões históricas a partir das questões agrárias que o personalizam. Entende-se nesse sentido que o agricultor em sua forma de trabalho já é um empreendedor nato, uma vez que cabe a ele a cada ano, observar o que plantar, qual melhor época, e como o mercado receberá o produto por ele semeado.

Uma vez delimitada a característica do local e o perfil a ser atendido cabe ainda observar quais são os entendimentos em torno da temática turismo e empreendedorismo a fim de compreender o grau de disposição das pessoas em desenvolver o turismo rural.

Esse esclarecimento foi fundamental às iniciativas individuais para fortalecimento do grupo de trabalho na pretensão de receber visitantes em seus sítios.

Para conheceras potencialidades e recursos existentes, entende-se que as oficinas de esclarecimento e capacitação para o turismo, observadas as estratégias de marketing são fundamentais para trazer as pessoas ao convívio das técnicas a serem aplicadas no roteiro e na organização da atividade produtiva.

Entende-se portanto que o objetivo principal desse trabalho é demonstrar a importância da capacitação dos produtores rurais a partir das estratégias de trabalho focados na caracterização da oferta, do entendimento sobre o produto e quais as maneiras adequadas de distribuição do produto "Turismo Rural em Nova Pontal - SP".

\section{METODOLOGIA}

O projeto desenvolvido no Assentamento Nova Pontal possui várias fases de trabalho. As oficinas detrabalho com a comunidade rural se desenvolveram a partir de temas como: turismo rural, roteiros turísticos, empreendedorismo, hospitalidade e associativismo. 
Nesse estudo descreve-se a metodologia de trabalho da Oficina Empreendedorismo no Turismo Rural; cuja atividade foi planejada de modo a orientar a participação ativa das pessoas baseada no enfoque participativo com vistas a garantir que as opiniões sejam apresentadas, discutidas e respeitadas de maneira democrática, partindo do princípio que as informações obtidas sejam importantes para a construção do conhecimento.

A sensibilização foi parte principal do trabalho. Nesse momento utilizou-se a pesquisa participativa por meio da técnica de Brainstorm para obtenção de informações sobre quais as dificuldades e expectativas em relação ao turismo rural, quais os interesses em aprendizagem, tempo e horário disponível para a realização das oficinas.

A escolha dos temas se deu baseada no estudo de assuntos básicos da administraçãodelineados às necessidades e objetivos a serem atendidos. Foram montadas fichas de estudo para discussão em plenária, que devido ao perfil de público foram discutidas de forma oral seguindo a estrutura ora apresentada:

10 Tema - Caracterização da Oferta

1) Solicitação aos participantes que apresentassem sua realidade para a caracterização da oferta em relação aos serviços e sua descrição prestados na propriedade rural.

2) Solicitação aos participantes que apresentassem sua realidade para a caracterização da oferta em relação aos produtos e sua descrição existentes e comercializados na propriedade rural.

2o Tema - Composto de Marketing

1) Definição de Produtoa fabricar e/ou vender e dos serviços a prestar dentro do que se propõe na propriedade rural e que possa atender ao turismo, incluindo temas como:

\begin{tabular}{|l|c|}
\hline \multicolumn{2}{|c|}{ Elementos doProduto } \\
\hline * Bem Físico; & $*$ Instalação; \\
* Serviços; & * Garantia; \\
* Características; & $*$ Linha de produtos; \\
* Nível de qualidade; & $*$ Embalagem; e \\
* Acessórios; & $*$ Marca \\
\hline
\end{tabular}

2) Definição da política de Distribuição dos produtos, nomeadamente os tipos de canais a utilizar e o número e tipo de intermediários.

\begin{tabular}{|l|r|}
\hline \multicolumn{2}{|c|}{ Elementos da Distribuição } \\
\hline Objetivos; & $*$ Tipos de Intermediários; \\
* Tipo de & $*$ Como lidar com transporte e \\
Canal; & armazenagem, entre outros \\
\hline
\end{tabular}


3) Definição da política de Comunicaçãoque inclui as estratégias de publicidade, relações públicas, promoções, entre outras, que visam aumentar a notoriedade dos produtos e das marcas.

\begin{tabular}{|l|c|}
\hline \multicolumn{2}{|c|}{ Elementos da Comunicação } \\
\hline * Composto de Promoção; & * Propaganda; \\
* Vendedores; & * Promoção de \\
& vendas; e \\
& * Publicidade \\
\hline
\end{tabular}

4) Definição da política de Preçoa fim de auxiliar a posicionar os produtos. É aqui que se define as suas margens de lucro e também custos, bem como estratégias de atratividade combinada com outros elementos do composto.

\begin{tabular}{|l|r|}
\hline \multicolumn{3}{|c|}{ Elementos de Preço } \\
\hline * Flexibilidade; & $*$ Níveis de preço; \\
$*$ Descontos; & $* \begin{array}{l}\text { Condições } \\
\text { especiais }\end{array}$ \\
\hline
\end{tabular}

Com os temas centrais definidos a equipe de (02) dois professores e (01) bolsista coordenaram o trabalho que ocorreu no Centro Comunitário de Nova Pontal em espaço aberto e coberto com a participação de (14) quatorze representantes do assentamento. As cadeiras foram dispostas em formato circular para ampliar a visão de todos de modo a flexibilizar e democratizar as falas e relatos. O papel do coordenador durante esse processo foi um elemento de equilíbrio entre os participantes. Ele atuou como moderador do grupo, captando ideias e mantendo-se imparcial diante de opiniões particulares; porém observando e encorajando falas e opiniões, mantendo-se como interlocutor no conjunto do trabalho e neutro em possíveis conflitos.

\section{RESULTADOS}

A apresentação do tema e os questionamentos em torno da realidade do grupo foi eficaz na observação de problemas comuns; e puderam nortear o trabalho personalizado à realidade daquela comunidade. A compilação de dados e discussões foram anotadas durante os trabalhos e serviram de base para a identificação da oferta.

Os quadros apresentados a seguir são um composto entre teoria e análise da realidade discutida durante a oficina. 
Quadro 1. Realidade da oferta

\begin{tabular}{|l|l|}
\hline \multirow{4}{*}{ Tema 1 - Caracterização da Oferta } & \multicolumn{1}{|c|}{ Realidade Nova Pontal } \\
\cline { 2 - 2 } & Existência de casa potencial para pousada \\
\cline { 2 - 2 } & Existência de cavalos para cavalgada \\
\cline { 2 - 2 } & Diversidade de animais para apreciação \\
\cline { 2 - 2 } & Potencial de apreciação da paisagem \\
\hline
\end{tabular}

Quadro 2. Produtos ofertados no assentamento

\begin{tabular}{|l|l|}
\hline \multirow{4}{*}{$\begin{array}{l}\text { Tema } 2 \text { - Relação aos produtos e sua descrição } \\
\text { existentes e comercializados na propriedade }\end{array}$} & Realidade Nova Pontal \\
\cline { 2 - 2 } \begin{tabular}{l} 
rural \\
\cline { 2 - 2 }
\end{tabular} & Piversidade de Oleirícolas \\
\cline { 2 - 2 } & Produção e venda de leite \\
\cline { 2 - 2 } & Produção de queijos \\
\cline { 2 - 2 } & Produção de frutas e doces diversos \\
\cline { 2 - 2 } & Potencial para almoço rural \\
\hline
\end{tabular}

Com relação ao tema 2 - Composto de Marketing

\begin{tabular}{|c|c|}
\hline Produto & Resultado \\
\hline Bem Físico & Adequado \\
\hline Serviços & Possuem possibilidade de atendimento a visitantes \\
\hline Característica & $\begin{array}{l}\text { Definição da identidade rural como assentamento e reconhecimento } \\
\text { da sua história }\end{array}$ \\
\hline Nível de qualidade & A melhorar \\
\hline Acessórios & A melhorar \\
\hline Instalação & A melhorar \\
\hline Garantia & Por se tratar de serviço não se aplica \\
\hline Linha de produtos & Amplo portfólio \\
\hline Embalagem; & A desenvolver \\
\hline Marca & Discutida e definida \\
\hline $\begin{array}{l}\text { Elementos da } \\
\text { Distribuição }\end{array}$ & Resultado \\
\hline Objetivos & Vendas locais \\
\hline Tipo de Canal & Varejo e vendas ao consumidor \\
\hline $\begin{array}{l}\text { Tipos de } \\
\text { Intermediários }\end{array}$ & Varejo \\
\hline $\begin{array}{l}\text { Como lidar com } \\
\text { transporte e } \\
\text { armazenagem, entre } \\
\text { outros }\end{array}$ & $\begin{array}{l}\text { Dada a perecibilidade dos produtos o espaço para armazenagem é } \\
\text { temporário e se mostra adequado }\end{array}$ \\
\hline
\end{tabular}

\begin{tabular}{|l|l|}
\hline $\begin{array}{l}\text { Elementos da } \\
\text { Comunicação }\end{array}$ & \\
\hline $\begin{array}{l}\text { Composto de } \\
\text { Promoção }\end{array}$ & Não há \\
\hline Vendedores & Os produtores \\
\hline Propaganda & Divulgação na mídia \\
\hline
\end{tabular}




\begin{tabular}{|l|l|}
\hline Promoção de vendas & \\
\hline Publicidade & Folder do roteiro rural \\
\hline Elementos de Preço & \multicolumn{2}{|l|}{} \\
\hline Flexibilidade & Variedade de café rural para composição do preço \\
\hline Desconto & Não há \\
\hline Níveis de preço & Médio \\
\hline Condições especiais & Atendimento de acordo com a demanda \\
\hline
\end{tabular}

\begin{tabular}{|l|l|}
\hline Elementos dePreço & \multicolumn{1}{c|}{ Resultado } \\
\hline Flexibilidade & Variedade do café rural para a composição do preço \\
\hline Desconto & Não há \\
\hline Níveis de Preço & Médio \\
\hline Condições especiais & Atendimento de acordo com a demanda \\
\hline
\end{tabular}

Inicialmente foram explanados os conceitos e a proposta da oficina. Após esse breve momento teórico as pessoas apresentaram-se uma a uma e iniciaram a exposição do tema sob uma perspectiva prática no contexto de sua realidade. Discussões surgiram, ora iniciadas pelo coordenador, ora pela própria comunidade.

A partir dos temas algumas questões e informações fundamentais foram levantadas. Dentre elas, destacam-se: a história do Assentamento Nova Pontal, as interações entre a população urbana e rural de Rosana, a preocupação com os impactos no meio ambiente e importância da conscientização e sensibilização de visitantes quanto ao espaço rural.

As dificuldades do processo de implantação da atividade turística e os impasses técnicos foram se diluindo ao longo do trabalho, uma vez que, os participantes perceberam que o ato de empreender é parte integrante do trabalho no campo. A p'ropria história da vinda dos produtores à região é um ato de empreendedorismo; a forma de distribuição dos produtos produzidos é empreender. Esses e outros exemplos inseridos nas tabelas (que aliou técnica e realidade) foram fundamentais à aprendizagem e ao encorajamento ao empreendedorismo.

\section{DISCUSSÃO}

O estudo do tema empreendedorismo aplicado a aprendizagem colaborativa em que o aprendiz é o agente transformador de seu conhecimento mostrou-se eficaz e altamente positivo no trabalho realizado no Assentamento Nova Pontal - SP .

A partir da junção da técnica ao conhecimento empírico e da inserção do cotidiano espaçohomem - atividade produtiva experienciada durante a oficina, entende-se que a relação social, econômica, cultural e educativa ocasiona modificações positivas, e permite ao turismo ser mais uma possibilidade de trabalho empreendedor no Assentamento Nova Pontal 


\section{CONCLUSÃO}

O conjunto de ações, a pró-atividade e empreendedorismo das pessoas envolvidas garantiu a visitação, e proporcionou a formaçãode um produto que já está atendendo ao público jovem estudante de Rosana - SP, numa proposta de turismo pedagógico em que os mesmos puderam conhecer os aspectos geográficos, a cultura e gastronomia local, a partir devisitas técnicas orientadas pelos professores e coordenadora do projeto. O Composto de marketing (Produto, Distribuição, Comunicação e Preço) auxiliaram ao entendimento do que pode e deve ser ofertado ao visitante, numa perspectiva de valorização dos bens locais e na mudança de visão da realidade, uma vez que os elementos apresentados passaram a ser entendidos como potenciais elementos ao ato de empreender a partir da ampla oferta de produtos e serviços detectados na oficina pelos próprios produtores rurais.

Certamente, esse foi o primeiro passo inclusive para aperfeiçoar o atendimento, a hospitalidade e os produtos numa perspectiva empreendedora.

\section{REFERÊNCIAS}

BRASIL. Turismo Rural: Orientações Básicas. MTUR, 2a ed. 2010. Disponível em: http://www.turismo.gov.br/export/sites/default/turismo/o_ministerio/publicacoes/downloads_p ublicacoes/Turismo_Rural_Versxo_Final_IMPRESSxO_.pdf. Acesso: 12 de ago 2014.

BRASIL. Diretrizes para o desenvolvimento do turismo rural. MTUR, s/d.Disponível em: http://www.turismo.gov.br/export/sites/default/turismo/o_ministerio/publicacoes/downloads_p ublicacoes/Diretrizes_Desenvolvimento_Turismo_Rural.pdf. Acesso: 10 outubro 2013.

DRUCKER, P. F. Inovação e espírito empreendedor: prática e princípios.São Paulo: Pioneira Thomson Learning, 2005.

KOTLER P. e KELLER, Kevin Lane. Administração de Marketing: A Bíblia do Marketing. 12a edição. Prentice Hall Brasil, 2006.

COBRA, M. Marketing de Turismo: Turismo, Lazer e Negócios. São Paulo: Cobra, 2005.

SWARBROOKE, J. e HORNER, S. O Comportamento do Consumidor no Turismo. São Paulo: Aleph, 2002. 